\title{
The Sealing Efficiency and Interaction between Purge Flow and Mainstream Flow for Novel Rim Seal Configurations
}

\author{
Ziqing Zhang \\ Institute of Engineering Thermophysics, \\ Chinese Academy of Sciences \\ University of Chinese Academy of Sciences \\ zhangziqing@iet.cn \\ Beijing, China
}

\author{
Wencan Tao \\ Institute of Engineering Thermophysics, \\ Chinese Academy of Sciences \\ University of Chinese Academy of Sciences \\ taowencan@iet.cn \\ Beijing, China
}

\author{
Yukuan Song \\ Institute of Engineering \\ Thermophysics, Chinese \\ Academy of Sciences \\ University of Chinese \\ Academy of Sciences \\ songyukuan@iet.cn \\ Beijing, China
}

\author{
Zhijun Lei \\ Institute of Engineering \\ Thermophysics, Chinese \\ Academy of Sciences \\ University of Chinese \\ Academy of Sciences \\ leizhijun@iet.cn \\ Beijing, China
}

\author{
Yanfeng Zhang \\ Institute of Engineering \\ Thermophysics, Chinese \\ Academy of Sciences \\ University of Chinese \\ Academy of Sciences \\ zhangyf@iet.cn \\ Beijing, China
}

\begin{abstract}
The rim seal is used to prevent the mainstream ingestion to the gap between the turbine vane and blade. In this research, the dolphin lip with a hook configuration and a large seal cavity with hook structures are designed based on the high-pressure turbine datum single shark lip rim seal configuration. Sealing effect and flow field parameters are measured by the experiment method, and numerical simulation is used to supplement the mechanism. For three configurations, the effect of leakage slot vortex on seal efficiency and the influence of leakage vortex generated by the interaction between purge flow and mainstream are discussed in depth.

The results show that the dolphin lip with hook structure form a reverse vortex which contrary to the leakage slot vortex to increase the sealing efficiency, and the large seal cavity makes the sealing efficiency is higher than the datum structure. With different purge flow rates and unequal seal structures, purge flow produces three types of leakage vortexes in the passage. Besides, the seal configuration with dolphin lip will produce Kelvin-Helmholtz instability at the interface between the purge flow and mainstream at a lower purge flow rate, and thus induce new leakage vortex branches in the blade passage.
\end{abstract}

\section{INTRODUCTION}

Complex seal structures are designed, and secondary air is introduced from the compressor as cooling flows into rim seal to prevent the ingestion of the mainstream. However, the leakage flow interacts with the secondary flow losses that have a significant negative impact on the aerodynamic performance of the turbine. Therefore, designing a suitable rim seal to balance the effects of sealing and the impact on the mainstream has become a research hotspot in recent years.

Schuler et al. ${ }^{[1]}$ found that axial overlapping compound geometry can more effectively prevent mainstream ingestion and reduce the height of the boundary layer lifted by the purge flow. Savov et al. ${ }^{[2]}$ compared the single and double lip rim seal geometries and found that the double lip rim seal requires less flow to achieve the same sealing efficiency. Erickson et al. ${ }^{[3]}$ proposed and compared the effects of "shark nose" and "dolphin nose" structures of the lip. The results show that the dolphin nose has better cooling efficiency than shark nose under different purge flow rates. However, due to the rapid lifting of the cooling airflow, a relatively large secondary flow loss is caused.

Mclean et al. ${ }^{[4]}$ found that reducing the radial momentum and the circumferential momentum difference between the purge flow and the mainstream can weaken the strength of the viscous shear layer near the hub. Similar conclusions 
were found in Rield et al. ${ }^{[5]}$, Hunter et al. ${ }^{[6]}$ and Gier et al. ${ }^{[7]}$. Jia and $\mathrm{Liu}^{[8]}$ classify the losses caused by the leakagemainstream interaction into four categories. These four losses are not independent of each other, the shear induced vortex and slot leakage vortex caused by the purge flow are found.

Instability will arise due to the flow property difference between the purge flow and the mainstream flow. Chilla et al. ${ }^{[9]}$ studied the flow interaction at the rim seal interface is found to be naturally unsteady, which produces a periodic vortex shedding into the rotor passage. Horwood et al. ${ }^{[10]}$ found that the instability of the outlet of the seal was caused by the tangential shear between the annulus and egress flows, and the instability under the large seal flow was completely suppression.

The previous research only focused on the property of flow passage with the purge flow, and did not analyze the vortex structure generated by the purge flow in the flow passage. In addition, the study of instability only concerns the occurrence of instability, and does not further discuss what the vortex generated by instability.

In this paper, based on datum seal configuration A with the single-lip shark nose, two new seal structures are designed. Through the experiments and numerical simulations of these three configurations, the flow structures with sealing effect and the vortex structure generated by the purge flow in the flow passages are specifically investigated. The influence of rim seal structure and purge flow rate on the sealing efficiency, flow loss, and blade loading is calculated and clarified. Moreover, mechanisms of the KelvinHelmholtz instability produced under certain operating conditions are discussed. These laws provide a better understanding of the general flow of the sealing structure.

\section{EXPERIMENTAL AND NUMERICAL METHODS}

\section{High-speed cascade test bench and sealing structure}

High-speed cascade test bench built by our research group is used in the experiment, as shown in Figure 1. The test section can set a rim seal configuration and a secondary air supply chamber configuration by replacing the turn table at the root of the blade. The mainstream air supply is provided by two centrifugal air compressors. The maximum supply pressure is $1.0 \mathrm{MPa}$ and the maximum supply flow is $5 \mathrm{~kg} / \mathrm{s}$. The sealing air supply is provided by a screw compressor which supply pressure is $1.2 \mathrm{MPa}$, and the maximum air supply flow rate is $0.25 \mathrm{~kg} / \mathrm{s}$. The flow rate of the purge flow entering the sealing structure is controlled by adjusting the flow difference between the inlet and outlet of the secondary air supply chamber.

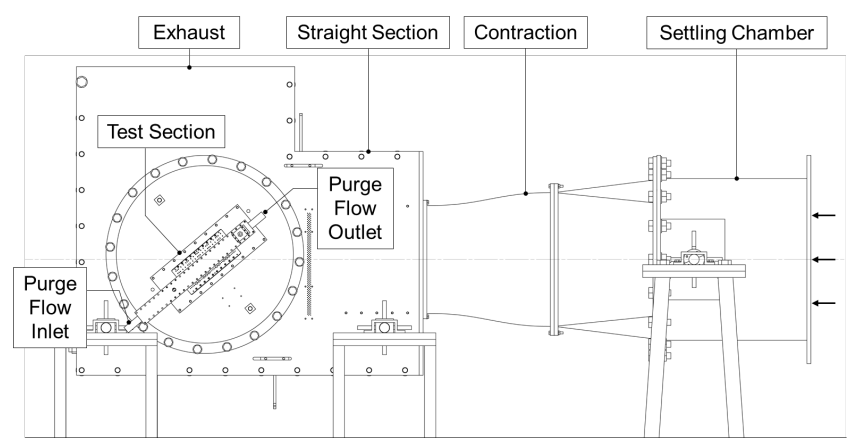

Figure 1 High-speed cascade test bench

In the analysis of the flow field, the $\mathrm{X}$ axis is set to the stream-wise axis, and the zero-plane locates at the origin position which at the leading edge of blade as shown in Figure 2. In terms of the measurement methods of test, the total pressure is measured at the inlet of test section and the inlet of the sealing configuration, and the pressure and velocity distribution of blade passage are measured by threehole probe at the $0.4 \mathrm{C}_{\mathrm{x}}$ position behind the cascade as shown in Figure 2. The static pressure hole is set on the surface of the blade. The load distribution of the blade is measured and the mass flowmeter is used to measure the mass flow of the sealing stream.

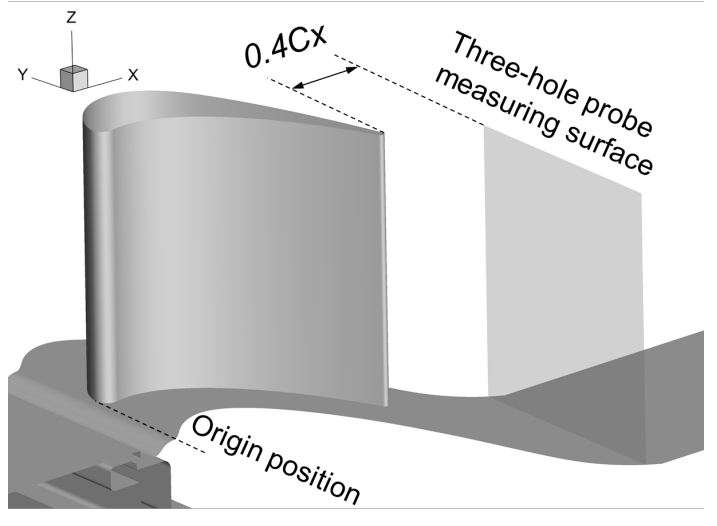

Figure 2 Test probe measurement position

The experiment uses a high-pressure turbine rotor cascade. Four straight blades, suction and pressure surface at the two ends respectively form five flow passages. The measurement is executed within 1.2 times pitch. The experiment uses designed outlet Mach number and designed incidence. The specific parameters of the cascade are listed in Table 1:

Table 1 High-pressure turbine rotor cascade parameters

\begin{tabular}{|c|c|}
\hline Parameters & Value \\
\hline Pitch, $\mathrm{S}$ & $50.445 \mathrm{~mm}$ \\
\hline Chord, $\mathrm{C}$ & $61.08 \mathrm{~mm}$ \\
\hline Axial chord, $\mathrm{C}_{\mathrm{x}}$ & $43.92 \mathrm{~mm}$ \\
\hline Solidity, $\mathrm{C} / \mathrm{S}$ & 1.21 \\
\hline Span, $\mathrm{h}$ & $120 \mathrm{~mm}$ \\
\hline Inlet flow angle, $\alpha_{1}$ & $42.6^{\circ}$ \\
\hline Incidence, $i$ & $1.4^{\circ}$ \\
\hline
\end{tabular}




\begin{tabular}{|c|c|}
\hline Outlet flow angle, $\alpha_{2}$ & $18.47^{\circ}$ \\
\hline Inlet Mach number, $\mathrm{Ma}_{1}$ & 0.26 \\
\hline Outlet Mach number, $\mathrm{Ma}_{2}$ & 0.89 \\
\hline
\end{tabular}

The object of this research is the rim seal structure in front of the turbine blade cascade. Figure 3 shows the three rim seal structures used in this study. A is datum configuration, which consists of a seal cavity and a shark nose seal lip. Seal configuration $B$, whose seal cavity remains constant, and the lip is changed to a dolphin nose with a hook structure at the lip lower surface. Its minimum clearance was located under the seal cavity. The characteristics of the dolphin nose are that the upper surface of the lip is far from the surface of the hub. Seal configuration $\mathrm{C}$, which is the same as the seal lip, its seal cavity area is enlarged and hook structures are arranged at the upper and lower surface exits of the cavity. The seal clearance of the three seal configurations is $0.8 \mathrm{~mm}$ which is shown in Figure 3.

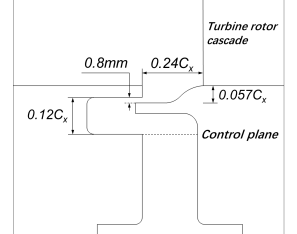

Seal A

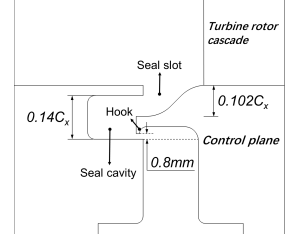

Seal B

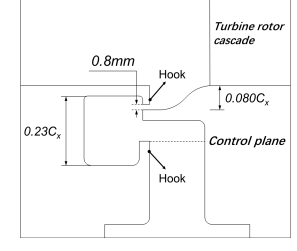

Seal C
Figure 3 Schematic diagram of three seal configurations

Table 2 High-pressure turbine seal configuration structural and flow parameters

\begin{tabular}{|c|c|}
\hline Parameters & Value \\
\hline Seal clearance, $\mathrm{d}$ & $0.8 \mathrm{~mm}$ \\
\hline Rated leakage fraction, $\mathrm{LF}^{*}$ & $1.0 \%$ \\
\hline Rated purge flow circumferential speed, $\mathrm{Vss}^{*}$ & $75 \mathrm{~m} / \mathrm{s}$ \\
\hline
\end{tabular}

\section{Numerical methods}

In the CFD calculation, to save computing resources, the calculation of the mid-span height is used to completely capture the endwall flow and the mainstream flow. The mesh is shown in Figure 4 which generated by the Gambit. The mesh nodes are all matched without interruption to ensure the accuracy of the calculation and the continuity of the streamline during post-processing. According to the verification of mesh independence, the total computation domain is divided into 5.38 million cells. The maximum $\mathrm{y}^{+}$ value is under 1.0, which can meet the precision requirements of the turbulence model.

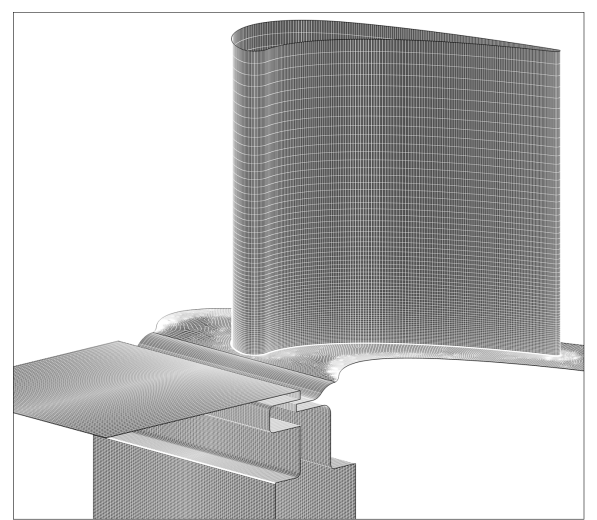

(a) Overall computational domain mesh

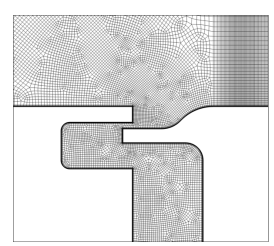

(b) Mesh distribution for rim seal geometry

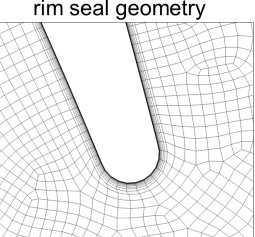
trailing edge (c) Mesh distribution for

Figure 4 Computational mesh in fluid domain

In terms of the solver, ANSYS CFX is used which adopts the finite volume method based on finite element method. In this study, the RANS method was used. After comparing with the experiment results, it was found that the results of the Reynolds stress term using the k-omega turbulence model to close the Navier-Stokes equations are more consistent with the experiment.

The mainstream boundary conditions for the inlet uses the actual radial total pressure distribution measured by the boundary layer probe. The sealing inlet boundary conditions are set to the speed in the circumferential direction to simulate the circumferential movement of the purge flow, and the radial direction is set to a certain speed to determine the purge flow rate.

Figure 5 shows the numerical simulation and experiment results comparison at the $1.4 \mathrm{C}_{\mathrm{x}}$ position shown in Figure 4 . It can be seen that the numerical simulation results are consistent with the experiment in total pressure coefficient contour and deviation distribution.

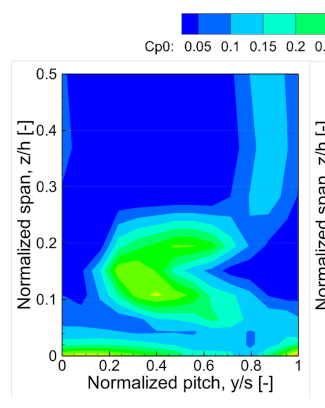

(a) Experiment

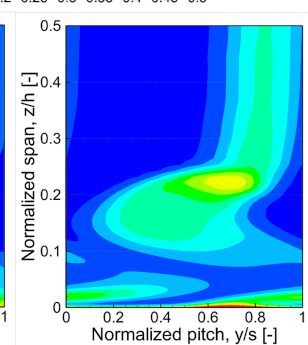

(b) Numerical Simulation

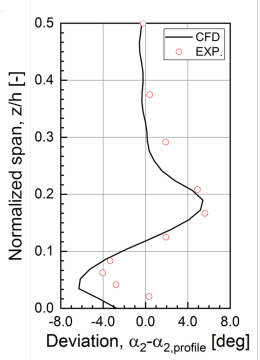

(c) Deviation verification
Figure 5 Numerical simulation and experiment results comparison at $1.4 C_{x}$

\section{RESULTS AND DISCUSSION}

\section{Sealing principle and purge flow characteristics}

In order to clarify the interaction of the two fluids in the same circumferential position when the mainstream ingests and explain vortex structure of preventing mainstream ingestion, a small purge flow ( $\mathrm{LF}=0.1 \%$ ) was chosen to study the interaction mechanism and sealing efficiency. The results of the experiment and numerical simulation show that 
the sealing effectiveness of the three seal structures are high, and the ingestion of the mainstream can be prevented under small purge flow.

The circumferential distribution of the mainstream ingestion and the sealing leakage can be seen according to the circumferential distribution of the radial Velocity $\mathrm{Z}$ of the horizontal plane of the seal slot outlet, as shown in the flood contour of Figure 6. Negative Velocity $Z$ represents ingestion and positive represents leakage. In addition, for the clear presentation, selecting three different pitch sections, which are the main ingestion side near the pressure side of the blade (Plane 1), the same trend of ingestion and leakage in mid- pitch (Plane 2), and the leakage is maximum (Plane 3). The streamline on three sections is drawn, the non-dimensional temperature is represrnted as colors, where blue represents the lower temperature purge flow and red represents the higher temperature mainstream.

In order to obviously characterize, the plane vortex which produce sealing effect in the seal slot or cavity is referred to Leakage Slot Vortex. The three-dimensional vortex in the blade passage induced by leakage slot vortex or other reasons when purge flow leaks to the mainstream is referred to Leakage Vortex.

$\theta: \quad 0 \quad 0.10 .20 .30 .40 .50 .60 .70 .80 .9 \quad 1$

$\begin{array}{lllllllllllll}\text { Velocityz: } & -8 & -6.4 & -4.8 & -3.2 & -1.6 & 0 & 1.6 & 3.2 & 4.8 & 6.4 & 8\end{array}$

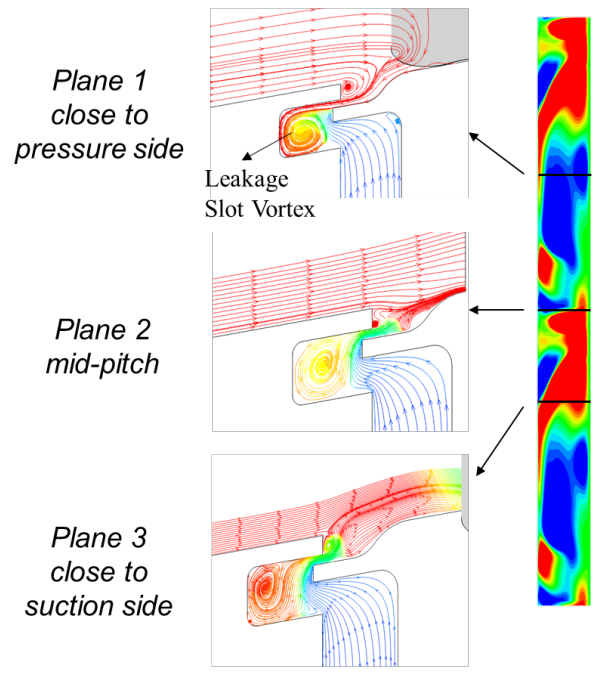

(a) Seal A

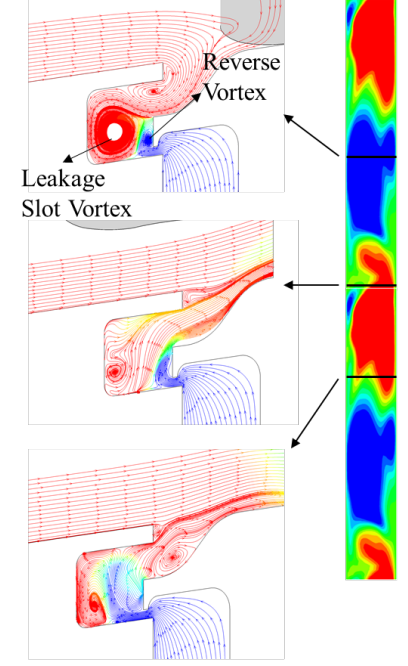

(b) Seal B

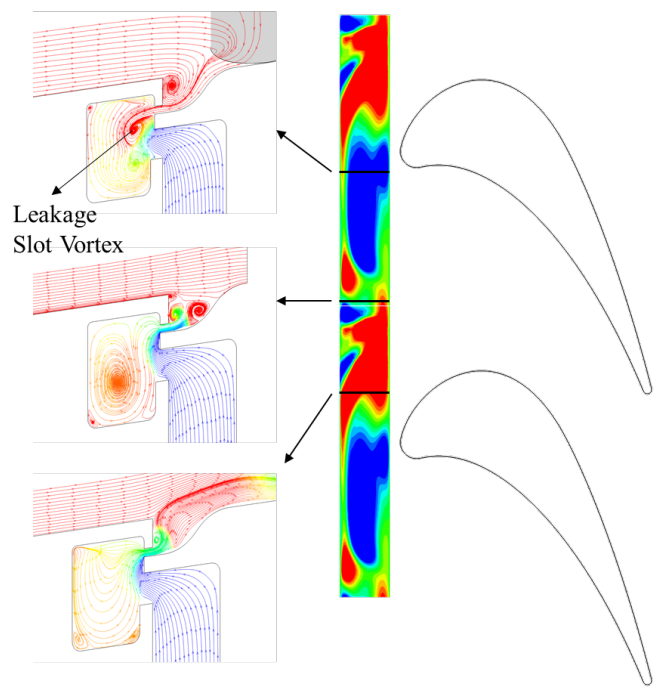

(c) Seal C

Figure 6 Mainstream ingestion and sealing vortex in $L F=0.1 \%$

The principles of preventing the mainstream ingestion for three seal configurations are distinct, thus the sealing effectiveness has difference with each other as shown in Figure 6. The sealing effectiveness is strictly related to the flow form in the seal structure, such as the fluid type, position, size of the leakage slot vortex and other small vortex structures. They are determined by the seal structure geometry and leakage fraction. The sealing effectiveness and flow loss of three configurations in $\mathrm{LF}=0.1 \%$ are shown in solid line of Figure 7.

For seal datum configuration $\mathrm{A}$, the mainstream passes through the minimum clearance and ingest the sealed cavity, forming leakage slot vortex in the cavity with the purge flow on Plane 1. In this position, the purge flow prevents further ingestion of the mainstream. However, the leakage slot vortex close to the disc chamber control surface, and the mainstream is mixed with the purge flow, causing the lower sealing effectiveness. Purge flow has little influence on the mainstream due to the leakage slot vortex is located far from the mainstream in the cavity so that the flow loss is the lowest.
For seal configuration $\mathrm{B}$, the mainstream ingests into the seal cavity largely, forming a leakage slot vortex in the seal cavity. On the other hand, a hook structure was set on the lower surface of lip to form a reverse vortex after purge flow out of the hook which contrary to the vortex direction of the leakage slot vortex, it can effectively prevent the mainstream ingests into the disk chamber, thus the sealing effectiveness of configuration $\mathrm{B}$ is high. But the leakage on the suction side is relatively high caused by the dolphin nose and the loss of $\mathrm{B}$ is slightly higher.

For seal configuration $\mathrm{C}$, the mainstream easily flow circumferentially in the cavity easily owing to the large seal cavity and it is difficult to continue the radial ingestion into the disc chamber and the leakage slot vortex is formed in the cavity by the mainstream and the purge flow. In addition, the hook structure on the lower surface of the seal cavity effectively prevents the ingestion into the disc chamber. For these reasons, the sealing effectiveness is relatively high, but the higher viscous dissipation of the purge flow produced due to the large seal cavity, resulting in greater flow loss. 


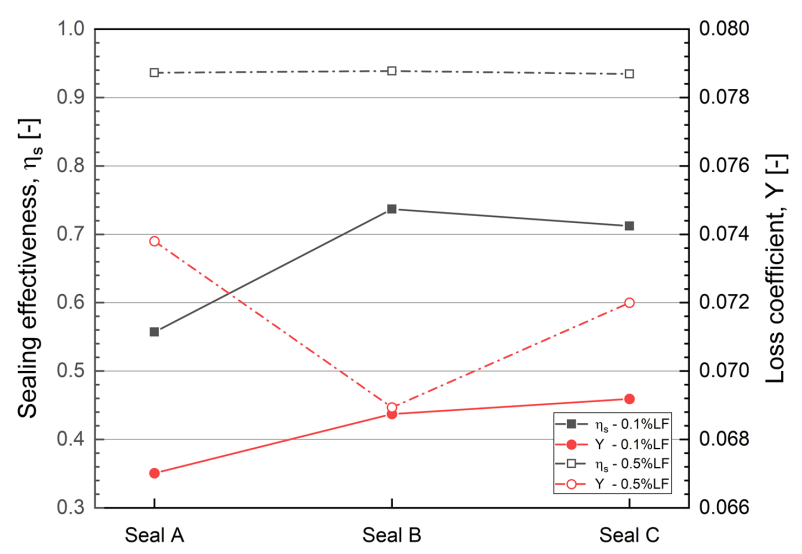

Figure 7 Sealing effectiveness and flow loss of three configurations in $\mathrm{LF}=0.1 \%, 0.5 \%$

Furthermore, the sealing effectiveness at a slightly larger purge flow rate are analyzed. Figure 8 shows that the distribution of the mainstream ingestion and purge flow leakage in $\mathrm{LF}=0.1 \%$ and $0.5 \%$ on Plane 1 . The reason for selecting Plane 1 for the sealing efficiency analysis is the large radial pressure gradient in the end wall region and the ingestion is the most serious are shown in Figure 6. Under the purge flow rate of $L F=0.5 \%$, the flow structure in the seal cavity is seriously reformed compared with $L F=0.1 \%$. The sealing effectiveness of the three configurations is significantly improved, and the purge flow is entirely developed and enter the mainstream. For the three seal configurations, the leakage slot vortex mainly composed of the purge flow will be formed in the seal cavity. But since the new purge flow structure has just formed stable under this purge flow rate, the difference between the three seal configurations is relatively slight, both reached about 0.94 . Because the effectiveness of configuration $B$ is inherently high, and that of $\mathrm{A}$ and $\mathrm{C}$ is greatly improved due to full leakage of the purge flow. Besides, the area of the leakage flow path of $\mathrm{A}$ and $\mathrm{C}$ are nearly identical, as shown in circle area of Figures 8 (d) and (f).

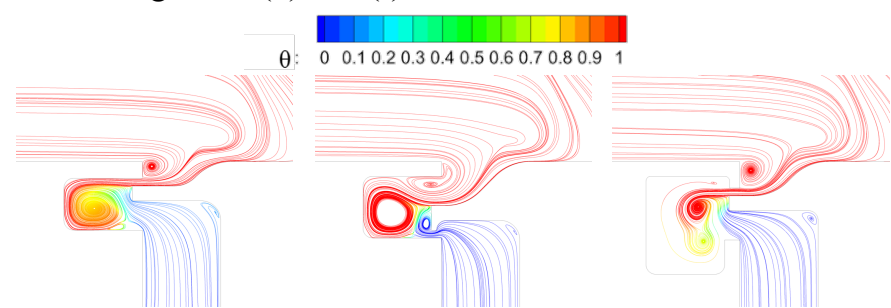

(a) $\mathrm{LF}=0.1 \%-$ Seal $\mathrm{A}$

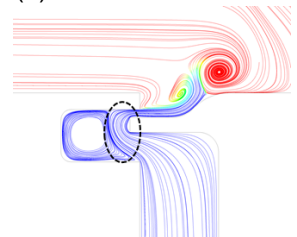

(d) $L F=0.5 \%-$ Seal A (b) $L F=0.1 \%-$ Seal $B$

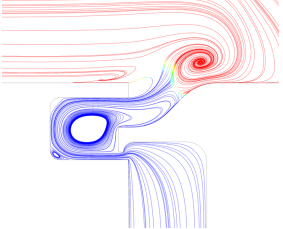

(e) LF $=0.5 \%$ - Seal B (c) LF $=0.1 \%-$ Seal C

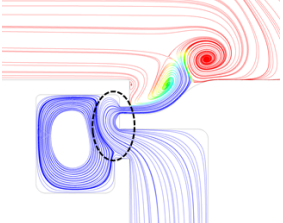

(f) $L F=0.5 \%-$ Seal C

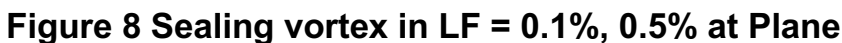
1 of three configurations
The temperature distribution of the intermediate height of the seal cavity inner surface is monitored as shown in Figure 9. The red line in subpicture indicates the detection position of seal A. Besides, the temperature monitor of seal B and $\mathrm{C}$ are in the same position. It can be seen that the seal configuration $\mathrm{B}>\mathrm{A}>\mathrm{C}$. A large part of the mainstream ingest into the seal cavity because the dolphin structure cause the temperature of the cavity of configuration $\mathrm{B}$ to be the highest. And the temperature of configuration $\mathrm{C}$ cavity is the lowest because the lower surface of the lip is far from the upper surface of the lower hook. Moreover, the large area of cavity causes a greater inflow of the purge flow to cool down the cavity. Therefore, from the perspective of preventing the high temperature mainstream from entering the seal cavity, the seal configuration $\mathrm{C}$ has the best effect.

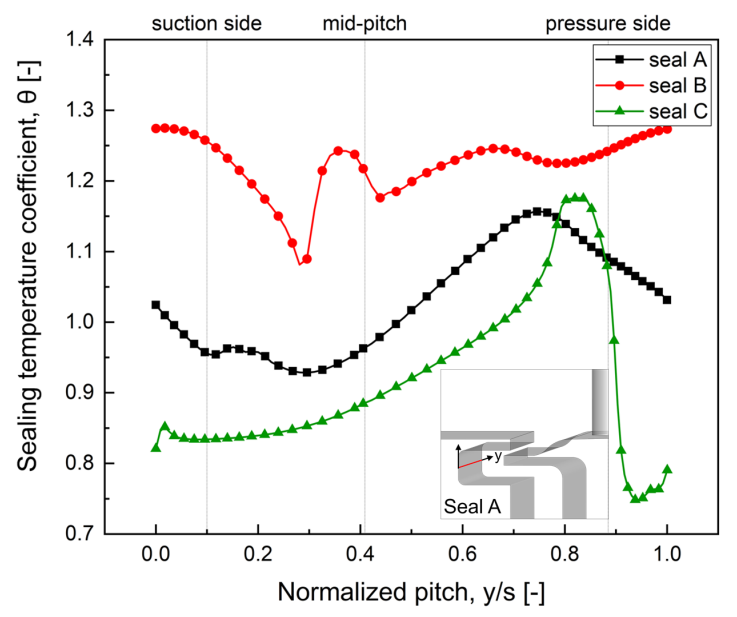

Figure 9 Seal cavity inner surface temperature
distribution in LF $=0.1 \%$

\section{Interaction between the purge flow and mainstream}

The vortex system of the blade passage was different from the unsealed structure primarily due to the formation of the leakage vortex. The purge flow out of the seal slot mainly forms three types of leakage vortex as shown in Figure 10.

The first type is the suction side leg of leakage vortex which is formed close to the suction side of the blade, and it is the most obvious vortex vary from conventional unsealed flow passage. The purge flow out of seal slot in blade leading edge hits the recirculation zone of the horseshoe vortex, and forms a counter-rotation as shown in box area of Figure 10, and develops the suction side leg of leakage vortex.

The second type is the pressure side leg of horseshoe vortex formed by purge flow at the blade leading edge pressure suction in higher purge flow rate. In this situation, the pressure side leg of horseshoe vortex consists of the boundary layer of mainstream and the partially leakage flow, this is different from the horseshoe vortex only formed by the mainstream boundary layer when the structure is unsealed.

The third type is the leakage vortex formed by purge flow at mid-pitch. In this position, the mainstream ingestion trend is the same as the purge flow leakage trend, and the leakage vortex is induced by the shear force between mainstream and purge flow. 
Figure 11 shows the typical flow structure in the blade passage with the seal structure. Therefore, the main component of the passage vortex becomes the joint action of the leakage vortex and the pressure side leg of horseshoe vortex.

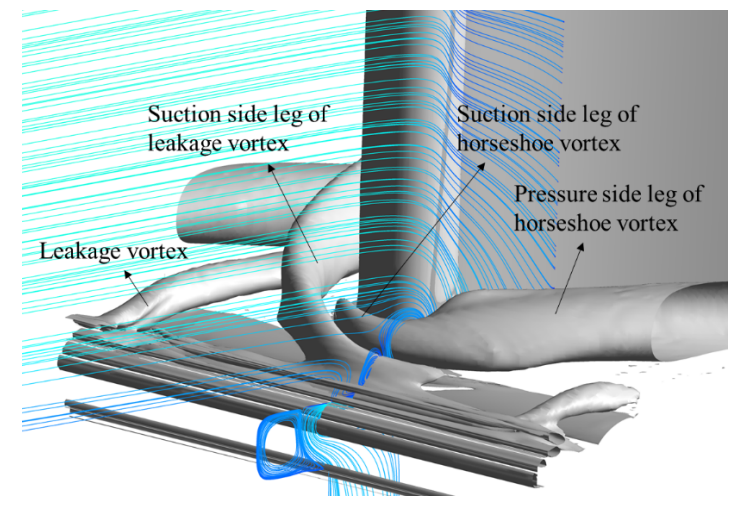

Figure 10 Vortex structure indentified by Q-criterion at the rim exit and the leading edge of blade

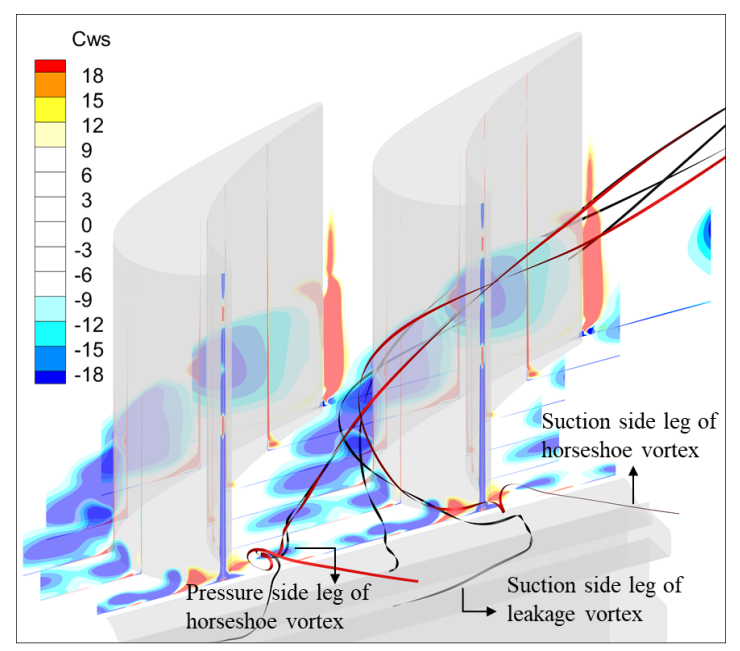

\section{Figure 11 The streamline and stream vorticity in the blade passage with seal $A$}

The purge flow will form unique vortex structures after entering the mainstream, where the structure is related to the purge flow rate. Figure 12 shows the three-dimensional flow streamline of only purge flow under different purge flow rates. Red colour represents positive streamwise vorticity value and blue represents negative value.

Under the minor purge flow rate of $\mathrm{LF}=0.1 \%$, the purge flow flows out only from the suction side and is far away from the suction side of the blade. The B configuration is the farthest because the purge flow which closes to the suction side of the blade will flow out directly, and the purge flow close to the pressure side of the blade is driven by the mainstream of the ingestion here to the suction side leg of leakage vortex of the next blade suction side. This is indicated by the arrow in the diagram of $\mathrm{B}$ configuration when the purge flow is minor. And the purge flow of B more keeps away to the suction surface of blade, because the mainstream will enter the seal slot largely for dolphin nose and drive purge flow away from the suction surface of the blade. In this situation, the purge flow only forms the leakage vortex by the shear force in mid-pitch seal slot, and intersects with the pressure side leg of the horseshoe vortex in blade passage. The suction side leg and pressure side leg of leakage vortex are not formed.

Under the slight large purge flow rate of $\mathrm{LF}=0.5 \%$, The purge flow of $\mathrm{A}$ and $\mathrm{C}$ configuration almost flows out from the entire circumference and forms three distinct leakage vortexes, as indicated in the Figures 12 (d) and (f). For the configuration $\mathrm{B}$, the purge flow still only flows out near the suction side, but different from that at $\mathrm{LF}=0.1 \%$, the vortex formed is the suction side leg of leakage vortex and the vortex formed by the Kelvin-Helmholtz instability, which will be explained in the next part.

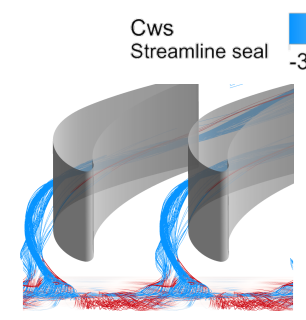

(a) LF $=0.1 \%$ - Seal $A$

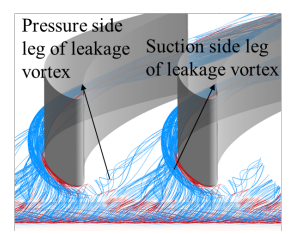

(d) LF $=0.5 \%$ - Seal A

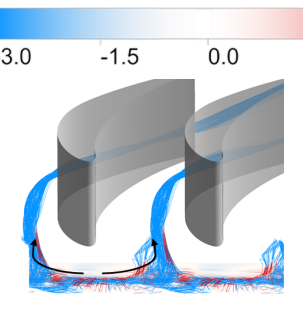

(b) $L F=0.1 \%$ - Seal $B$

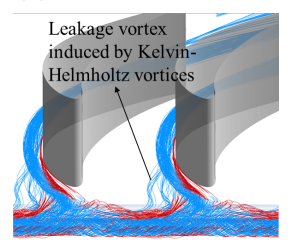

(e) LF $=0.5 \%$ - Seal B

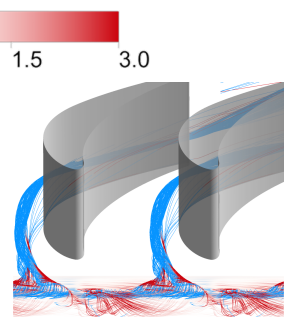

(c) LF $=0.1 \%-$ Seal C

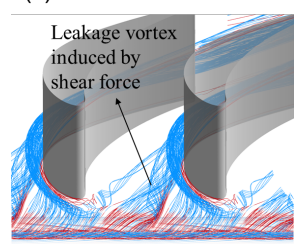

(f) $L F=0.5 \%-$ Seal C

\section{Figure 12 Purge flow streamline of variable purge flow rates for three seal configurations}

It is worth noting that as the purge flow rate increases to $0.5 \%$, the degree of leakage of the purge flow is close to the mainstream ingestion, and the Kelvin-Helmholtz instability occurs on the suction side of the seal outlet surface of the configuration B as shown in Figure 13. Figure 13(a) shows the static pressure distribution on the pitch plane where instability occurs at the rim, indicating that high pressure and low pressure regions appear in turn in the circumferential direction. The low pressure region in the shear layer produced by the mainstream and the purge flow indicates that there is Kelvin-Helmholtz vortices in this region. Figure 13(b) is pressure distribution on the straight line cross the vortices core in the 13(a), it can be seen that in the region where instability occurs, the pressure has a sharp change and shake, which can also verify the Kelvin-Helmholtz instability occurred. Figure 13(c) shows pitch plane circumferential velocity distribution contour and the radial velocity of the rim outlet horizon plane in unstable region. Since the mainstream and the seal flow have opposite circumferential speeds, according to the interface of the two circumferential speeds, it can be seen that the Kelvin-Helmholtz instability will cause intense blending between the mainstream and purge flow to form multiple vortices in the shorter circumferential distance. 


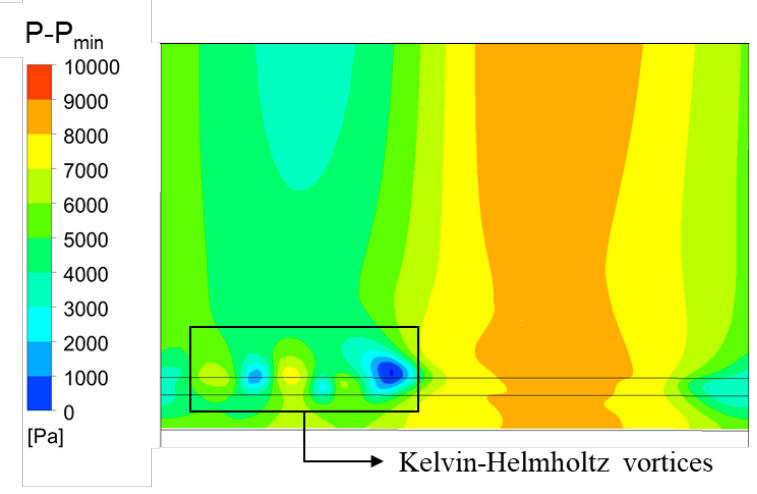

(a) Pressure contour of seal outlet pitch plane

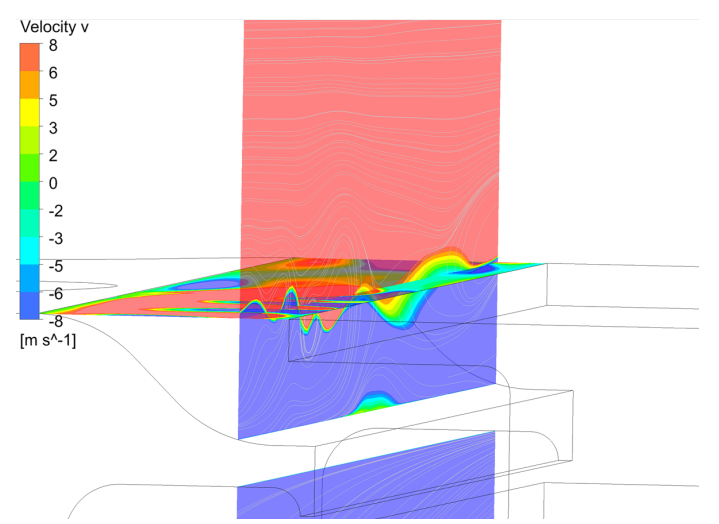

(c) Circumferential velocity contour of seal outlet pitch plane

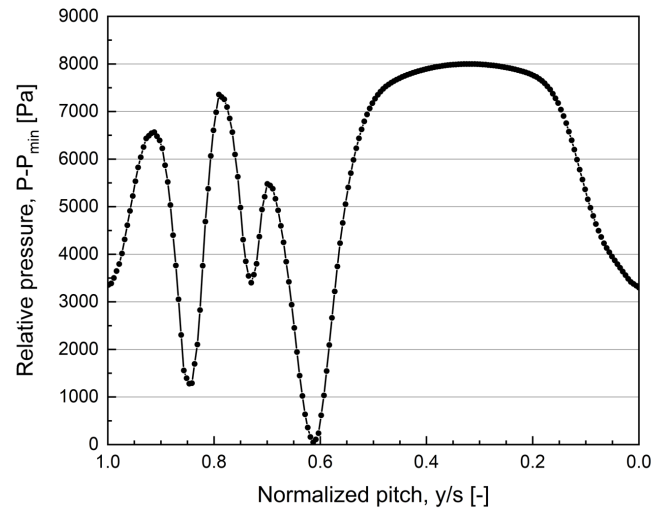

(b) Pressure of the line cross the vortices core

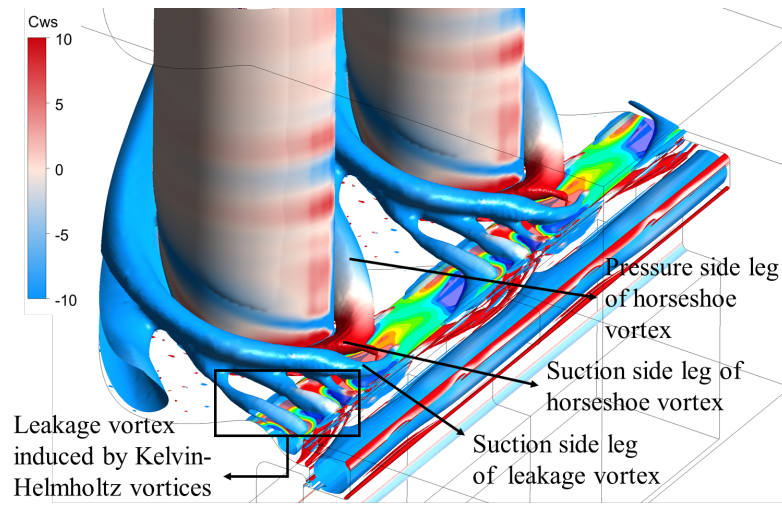

(d) Identification of vortex by Q-Criterion

Figure 13 Kelvin-Helmholtz vortices at seal slot outlet

Figure 13(d) shows that the vortex structure near the endwall in the fluid domain by the Q criterion. The criterion value is $4.963 \times 10^{7}$. The Kelvin-Helmholtz vortices generated on the pitch plane will form three new leakage vortexes on the suction side through a mixture of the purge flow out of the seal slot and the mainstream low-energy boundary layer fluids, which different from the suction side leg of leakage vortex, as shown in the black box section. From the colour of non-dimensional streamwise vorticity, the direction of rotation of the new leakage vortex is identical to that of the suction side leg of leakage vortex, and it merges into the suction side leg of leakage vortex after a remoteness. However, there is no significant negative impact on the flow loss of this condition due to the slight leakage vortex intensity.

The flow direction of the purge flow is investigated separately. The purge flow lines are shown in Figure 14 and Figure 15, the blue colour represents the negative streamwise vorticity, and the red represents the positive streamwise vorticity. Firstly, most of the purge flows flowing out from different circumferential positions are anticlockwise rotated, and is recognized by the Q criterion with mainstream, as shown in the grey isosurface in Figure 14. Then, with the development of the flow, the purge flow flows to the suction side of the blade through the suction side leg or pressure side leg of leakage vortex. The purge flow will be completely involved in the secondary vortex in the passage, and there is no part of purge flow straight with the mainstream, and it rises radially as the mainstream low-energy flow develops due to the low energy of the purge flow. Divided into two parts at about $0.6 \mathrm{C}_{\mathrm{x}}$, one part still rotates anticlockwise with the leakage vortex into the passage vortex. Another part flow into the wall vortex which the direction of rotation is opposite to the passage vortex, and it will merge with the trailing shed vortex downstream. In addition, a small part of the purge flow remain in the root of the blade as part of the corner vortex when the purge flow rate is large, as shown in Figure 15.

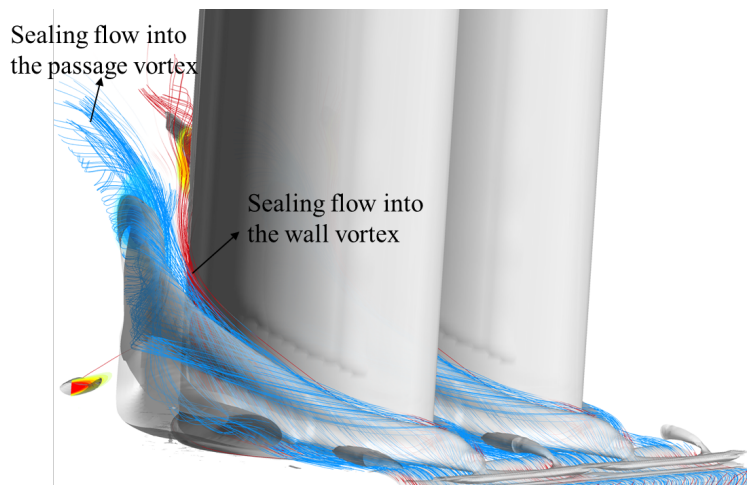

Figure 14 The development of purge flow in the blade passage 


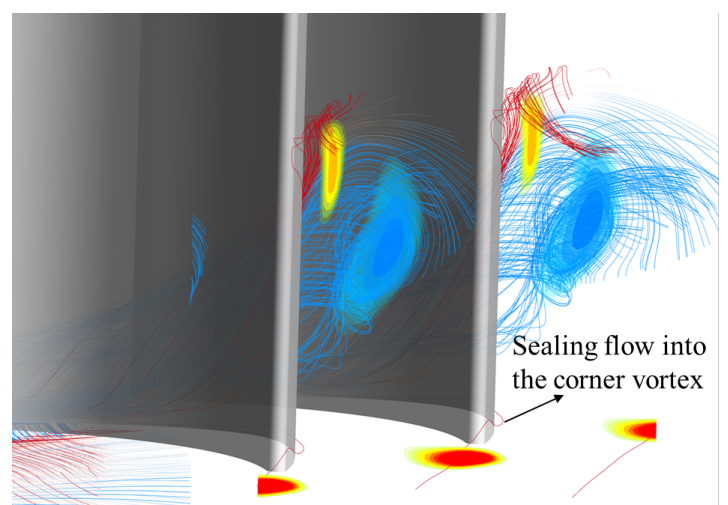

\section{Figure 15 Distribution of purge flow at the trailing edge of the blade}

The isoline of the total pressure coefficient and contour of the streamwise vorticity coefficient at $1.4 \mathrm{C}_{\mathrm{x}}$ are shown in Figure 16. There are three kinds of vortex structures in the trailing edge section. The blue region shows passage vortex composed of the leakage vortex, the pressure side leg of horseshoe vortex and part small leakage vortex. The streamwise vorticity value is negative, indicating that the vortex is rotated anticlockwise. The second vortex structure is trailing shed vortex, which corresponds to the orangeyellow region on the upper right, and its streamwise vorticity value is positive, indicating that the vortex is clockwise. The third vortex structure is corner vortex which is the red region on the bottom, the streamwise vorticity value is positive and the value is large, indicating that the vortex intensity is high.

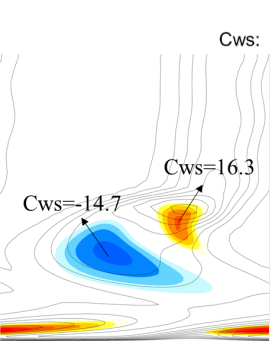

(a) LF $=0.1 \%-$ Seal $A$

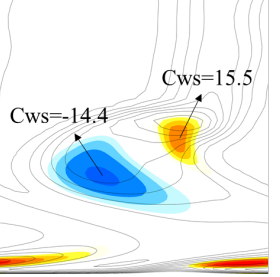

(d) LF $=0.5 \%-$ Seal $A$

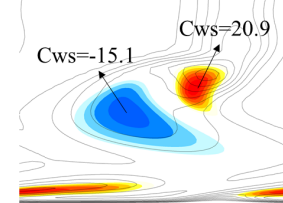

(b) LF $=0.1 \%-$ Seal $B$

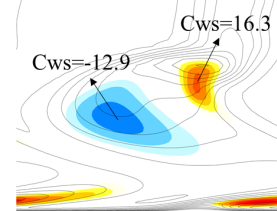

(e) LF $=0.5 \%-$ Seal $B$

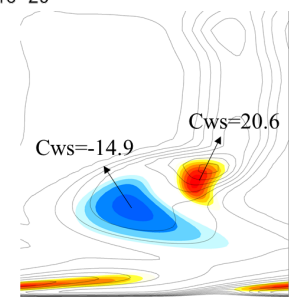

(c) LF $=0.1 \%-$ Seal C

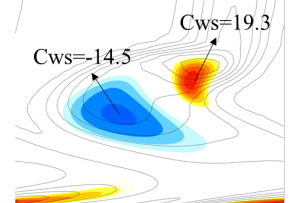

(f) $L F=0.5 \%-$ Seal C
Figure 16 Streamwise vorticity coefficient contour and total pressure coefficient isoline at $1.4 C_{x}$

The trend of intensity of the secondary vortex in variable purge flow rate for three configurations is analysed from the contour. Under the minor purge flow rate $\mathrm{LF}=0.1 \%$, the secondary vortex intensity of configuration $\mathrm{B}$ is the largest, the $\mathrm{C}$ is second, and the $\mathrm{A}$ is the smallest, which is correspond with the loss coefficient $\mathrm{Y}$ that loss of $\mathrm{B}$ is maximum as shown in Figure 7. Because under the small purge flow rate, the dolphin structure of the configuration $\mathrm{B}$ causes the radial velocity of the purge flow into the mainstream to be relatively large, and almost all of the purge flow is at a higher span position in passage as shown in Figure 12(b), thus the secondary flow intensity is enhanced.

At a higher purge flow rate $\mathrm{LF}=0.5 \%$, the intensity of secondary vortex decreases slightly, and was the smallest for configuration $\mathrm{B}$ of the three configurations. The purge flow of configuration B only flows out on the suction side of the blade, and the mainstream low-energy boundary layer fluid is fully mixed with the purge flow in the seal slot of the dolphin nose lip structure. The purge flow has relatively high kinetic energy which increases the energy of the mainstream lowenergy boundary layer fluid, which is beneficial to weaken the secondary flow intensity.

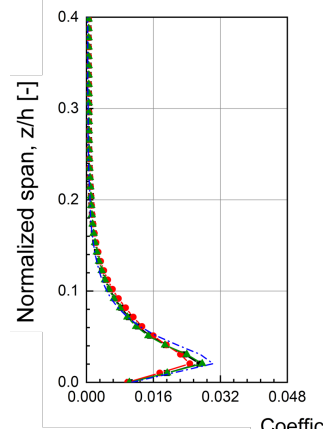

(a) $x / C_{x}=0.0$

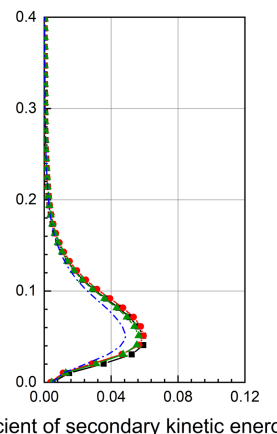

(b) $x / C_{x}=0.2$

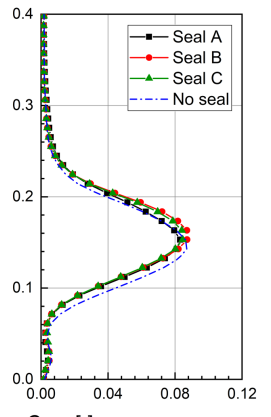

(c) $x / C_{x}=1.4$
Figure 17 Pitchwise mass averaged coefficient of secondary kinetic energy in LF $=0.1 \%$

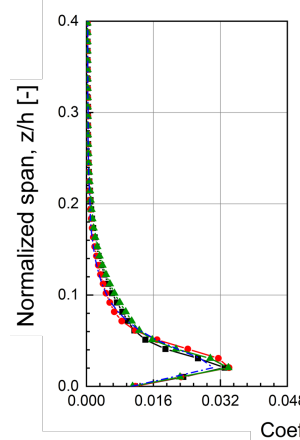

(a) $x / C_{x}=0.0$

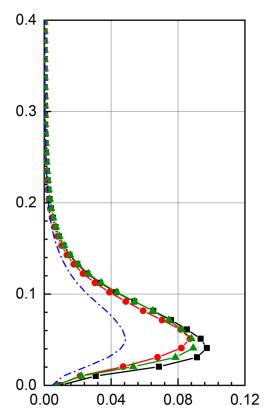

(b) $x / C_{x}=0.2$

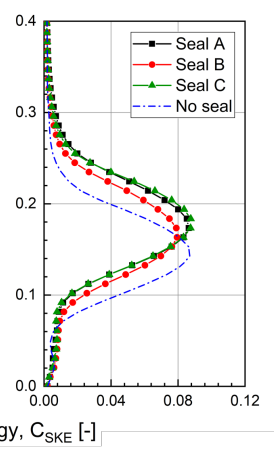

(c) $x / C_{x}=1.4$

\section{Figure 18 Pitchwise mass averaged coefficient of secondary kinetic energy in LF $=0.5 \%$}

The radial distribution of secondary kinetic energy for structure without seal and three seal configurations in LF = $0.1 \%$ and $0.5 \%$ are shown in Figure 17 and 18 . It can be seen that the purge flow will increase the strength of the secondary flow intensity in the front streamwise of the blade, such as at the $0.2 \mathrm{C}_{\mathrm{x}}$. At the downstream $40 \%$ axial chord of the trailing edge of the blade, the height of the passage vortex increases, and the intensity of the secondary flow is less affected compared to the structure without seal. For different types of seal structures, the same results as the vorticity contour can be obtained: in $\mathrm{LF}=0.1 \%$, the passage vortex intensity of the seal configuration B is the largest; in LF = $0.5 \%$, the passage vortex intensity and the span height of the 
configuration B is lowest. Besides, the intensity of corner vortex will increase with the purge flow rate increasing as shown in $\mathrm{C}_{\mathrm{SKE}}$ of the root of the blade in Figures 17(c) and Figure 18(c).

For the root loading distribution of the blade with seal structures as shown in Figure 19(a), the purge flow will reduce the leading edge loading of the blade and increase the trailing edge load. For the mid-span load (40\% full span) as shown in Figure 19(b), the loading of the rear increases, and aft-loading characteristics of the blade are more obvious.

The loading from the middle to the trailing edge of the blade increases because the suction side leg of leakage vortex will reduce the pressure of the blade suction surface when it develops to an appropriate height, as shown in the circular area of Figure 19(a).

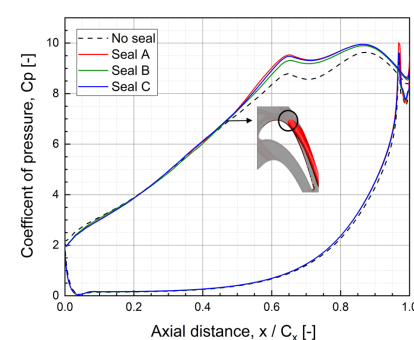

(a) $10 \%$ span

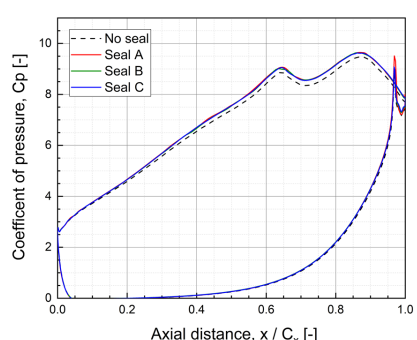

(b) $40 \%$ span
Figure 19 Blade loading of the three configurations in $\mathrm{LF}=\mathbf{0 . 5 \%}$

\section{CONCLUSIONS}

In this research, the aerodynamic performance of three seal configurations is studied by numerical simulation and experiment verification. The main conclusions are followed:

1. The leakage slot vortex and the reverse vortex generated by the hook of the lip lower surface, and increasing of the seal cavity area are beneficial to the sealing effectiveness. The lower half of the seal structure will affect the form of the leakage slot vortex and the mainstream ingestion, which affect the sealing effectiveness.

2. The most obvious characteristic with the purge flow is the formation of the three types leakage vortex. Besides, purge flow will merge into the corner vortex to enhance the intensity of the vortex. And the key factor affecting the magnitude of the secondary flow loss is the structure of the upper part of the seal, which decides the leakage flow form.

3. The Kelvin-Helmholtz instability arises in the dolphin lip configuration. This phenomenon occurs only when the upper face of the lip is far from the hub. And the new leakage vortex branches caused by Kelvin-Helmholtz vortices are discovered.

4. For the blade loading, the characteristics of the aftloading are more prominent due to the purge flow. The configuration with dolphin lip is less affected compared shark lip under the minor purge flow rate.

\section{NOMENCLATURE}

LF

$\dot{\mathrm{m}}$

$\alpha$

$\eta_{\mathrm{s}}$

Y

$\mathrm{CP}_{\mathrm{P}}$

$\mathrm{C}_{\mathrm{P} 0}$

$\mathrm{C}_{\mathrm{ws}}$

$\theta$

1

2

S1

Co
Leakage Fraction $[\%]=\frac{\dot{m}_{S}}{\dot{m}_{1}}=\frac{\dot{m}_{\text {in }}-\dot{m}_{\text {out }}}{\dot{m}_{1}}$

Mass flow rate

Airflow angle $\left[^{\circ}\right]$

Sealing effectiveness $=\frac{T_{1}^{\prime \prime}-T_{C o}{ }^{\prime \prime}}{T_{1}^{\prime \prime}-T_{S 1}{ }^{\prime \prime}}$

Loss coefficient $=\frac{P_{0, E F F}{ }^{\prime \prime}-P_{02} "}{P_{01}{ }^{\prime \prime}-P_{2}}$

Pressure coefficient $=\frac{P_{01}{ }^{\prime \prime}-P}{P_{01}{ }^{\prime \prime}-P_{1}^{\prime \prime}}$

Total pressure coefficient $=\frac{P_{01}{ }^{\prime \prime}-P_{0}}{P_{01}{ }^{\prime \prime}-P_{2}}$

Streamwise vorticity coefficient

Sealing temperature coefficient $=\frac{T-T_{S 1}{ }^{\prime \prime}}{T_{1}{ }^{\prime \prime}-T_{S 1}{ }^{\prime \prime}}$

Plane mass-average value

Inlet of mainstream

Outlet of mainstream, $1.4 \mathrm{C}_{\mathrm{x}}$ of blade

Inlet of purge flow

Control Plane

\section{REFERENCES}

[1] Schuler, P., Kurz, W., Dullenkopf, K., and Bauer, H. J. (2010, October). The influence of different rim seal geometries on hot-gas ingestion and total pressure loss in a low-pressure turbine. In ASME turbo expo 2010: power for land, sea, and air (pp. 1123-1134). American Society of Mechanical Engineers. doi:10.1115/GT201022205

[2] Savov, S. S., Atkins, N. R., and Uchida, S. (2017). A comparison of single and double lip rim seal geometries. Journal of Engineering for Gas Turbines and Power, 139(11), 112601. doi: 10.1115/1.4037027

[3] Erickson, R., and Simon, T. W. (2009). Effects of stator/rotor leakage flow and axisymmetric contouring on endwall adiabatic effectiveness and aerodynamic loss. In ICHMT DIGITAL LIBRARY ONLINE. Begel House Inc.. doi: 10.1615/ICHMT.2009.HeatTransfGasTurbSyst. 270

[4] McLean, C., Camci, C., and Glezer, B. (2001, June). Mainstream Aerodynamic Effects Due to Wheelspace Coolant Injection in a High-Pressure Turbine Stage: Part I-Aerodynamic Measurements in the Stationary Frame. In ASME Turbo Expo 2001: Power for Land, Sea, and Air (pp. V003T01A006-V003T01A006). American Society of Mechanical Engineers. doi:10.1115/2001-GT-0119

[5] Reid, K., Denton, J., Pullan, G., Curtis, E., and Longley, J. (2006, January). The effect of stator-rotor hub sealing flow on the mainstream aerodynamics of a turbine. In ASME turbo expo 2006: power for land, sea, and air 
(pp. 789-798). American Society of Mechanical Engineers. doi:10.1115/GT2006-90838

[6] Hunter, S. D., and Manwaring, S. R. (2000, May). Endwall Cavity Flow Effects on Gaspath Aerodynamics in an Axial Flow Turbine: Part I-Experimental and Numerical Investigation. In ASME Turbo Expo 2000: Power for Land, Sea, and Air (pp. V001T03A111V001T03A111). American Society of Mechanical Engineers. doi:10.1115/2000-GT-0651

[7] Gier, J., Stubert, B., Brouillet, B., and De Vito, L. (2005). Interaction of shroud leakage flow and main flow in a three-stage LP turbine. Journal of Turbomachinery, 127(4),

649-658 doi:10.1115/1.2006667

[8] Jia, W., and Liu, H. (2014, June). Numerical investigation of the interaction between upstream purge flow and mainstream in a highly-loaded turbine. In ASME Turbo Expo 2014: Turbine Technical Conference and Exposition (pp. V02CT38A012V02CT38A012). American Society of Mechanical Engineers. doi:10.1115/GT2014-25501

[9] Chilla, M., Hodson, H., and Newman, D. (2013). Unsteady interaction between annulus and turbine rim seal flows. Journal of Turbomachinery, 135(5), 051024. doi: 10.1115/1.4023016

[10] Horwood, J. T., Hualca, F. P., Wilson, M., Scobie, J. A., Sangan, C. M., and Lock, G. D. (2018, June). Unsteady Computation of Ingress Through Turbine Rim Seals. In ASME Turbo Expo 2018: Turbomachinery Technical Conference and Exposition (pp. V05BT15A012-V05BT15A012). American Society of Mechanical Engineers. doi:10.1115/GT2018-75321 